\title{
AUTISMO e CONFORTO AMBIENTAL
}

\section{AUTISM AND ENVIRONMENTAL COMFORT}

\author{
Marcia Troncoso ${ }^{1}$ \\ Neusa Cavalcante ${ }^{2}$ \\ (1) Universidade de Brasília (UnB) \\ e-mail:marciaurbanotroncoso@gmail.com \\ (2) Universidade de Brasília (UnB) \\ e-mail:neusa.cavalcante2@gmail.com
}

Palavras-chave: Autismo, Percepção sensorial, Conforto Ambienta.

\section{RESUMO}

O presente artigo trata de chamar a atenção para as necessidades dos autistas, no que se refere à sua relação com o ambiente construído. Apoiado em depoimentos de especialistas, familiares e dos próprios portadores desse especial transtorno e acreditando que a arquitetura e o urbanismo podem contribuir para a adaptação e o desenvolvimento desses indivíduos especiais, busca-se refletir sobre quais diretrizes devem orientar projetos de espaços ao ar livre mais adaptados e inclusivos. Entendendo que as necessidades dos portadores de Transtorno do Espectro Autista (TEA) envolvem, sobretudo, questões de caráter sensorial, admite-se que as soluções destas dizem respeito também ao campo da ergonomia e do conforto ambiental, vistos aqui sob uma ótica ampliada.

Keywords: Autism, Sensory perception, Environmental comfort.

\section{ABSTRACT}

This article intends to draws attention to the needs of autistic individuals, in relation to their relationship with the built environment. Supported by testimonials from experts, family members and those who present this particular disorder, and believing that architecture and urbanism can contribute to adaptation and development of these special individuals, we seek to reflect about what guidelines that should orient projects for more adapted and inclusive outdoor spaces. Understanding that the needs of patients with Autistic Spectrum Disorders (ASD) involve, above all, questions of a sensorial nature, it is admitted that their solutions also concern field of ergonomics and environmental comfort, seen here in a broader perspective. 
$16^{\circ}$ USIHC - Congresso Internacional de Ergonomia e Usabilidade de Interfaces Humano Computador

CINAHPA | 2017 - Congresso Internacional de Ambientes Hipermídia para Aprendizagem.

\section{INTRODUÇÃO}

Segundo dados atuais do Center of Disease Control and Prevention $(C D C)^{l}$, nos últimos 30 anos, a incidência de casos de Transtorno do Espectro Autista (TEA) aumentou 600\%. Em 2008, estimava-se, nos Estados Unidos, 1 caso para cada 88 crianças e, em apenas dois anos, essa proporção cresceu $30 \%$, passando, em 2010, para 1 caso a cada 68. Este quadro demonstra a urgência da oferta de espaços inclusivos, internos e externos, para indivíduos que passam a maioria do tempo isolados no interior de suas casas, inseguros, com pouca autonomia, e dependendo de cuidadores para sobreviver.

No entanto, a despeito da alta incidência de casos, não existem discussões sobre o problema da acessibilidade e do conforto desses indivíduos nas cidades contemporâneas. Por outro lado, muitas obras recentes, escritas por especialistas, familiares ou pelos próprios portadores do transtorno, têm trazido à luz uma série de informações importantes, que, servindo de subsídio para esse debate, podem contribuir para a elaboração de projetos de espaços arquitetônicos e urbanísticos mais adequados e inclusivos.

Após um breve retrato sobre as características dos fenômenos que afetam os portadores de TEA, pretende-se nesse artigo levantar a hipótese de que uma linguagem arquitetônica lúdica e abstrata poderia dialogar melhor com os autistas, no sentido de gerar uma empatia destes com seu entorno espacial, passando maior segurança e prazer ao se conectarem com o mundo a sua volta. Além disso, como as necessidades dos portadores de TEA envolvem questões de caráter sensorial, não seria errado admitir que as soluções destas dizem respeito também ao campo da ergonomia e do conforto ambiental, vistos então sob uma ótica ampliada.

\footnotetext{
${ }^{1}$ http://www.autism-society.org/what-is/facts-andstatistics/
} realizaça: Realização:

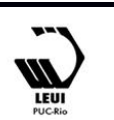

(1)

\section{DESENVOLVIMENTO}

A comunicação do ser humano com seu entorno é feita por meio dos cinco sentidos: visão, audição, olfato, paladar e tato. $\mathrm{E}$ foi a evolução dessas formas de perceber o meio ambiente que ajudou a nossa espécie a sobreviver no planeta. Mas o que acontece quando estas percepções funcionam de forma diferente do que é considerado normal? Em seu livro $O$ cérebro autista: pensando através do espectro, Temple Grandin (2014) afirma que nove entre dez pessoas com autismo apresentam um ou mais transtornos sensoriais que interferem na sua capacidade de gostar e sentir prazer em um mundo difícil de ser codificado.

Suspeito que os pesquisadores simplesmente não entendem a urgência do problema. Eles não conseguem imaginar um mundo onde roupas que pinicam o fazem sentir-se pegando fogo, ou onde uma sirene soa como se alguém estivesse perfurando meu crânio com uma furadeira... como socializar pessoas que não toleram o ambiente onde devem se mostrar sociáveis..? (GRANDIN, 2016, p. 80)

Compreender o contexto de uma situação pode ser algo muito complicado quando o cérebro não consegue decifrar bem as sensações percebidas pelo nosso corpo. Em sua obra How can I talk if my lips don't move?: inside my autistic mind (2011), Mukhopadhyay relata que possui dois eus, um atuante, estranho e cheio de energia, e outro pensante.

Enxergando-se como peças, como uma mão ou uma perna, afirma que costumava girar em círculos para poder juntar as partes num todo. De fato, para compensar algumas alterações cerebrais, as pessoas com TEA tendem a repetir suas ações em uma busca obstinada pelo equilíbrio, o que os faz muitas vezes desenvolver talentos. 
$16^{\circ}$ Ergodesign - Congresso Internacional de Ergonomia e Usabilidade de Interfaces Humano Tecnológica: Produto, Informações Ambientes Construídos e Transporte

$16^{\circ}$ USIHC - Congresso Internacional de Ergonomia e Usabilidade de Interfaces Humano Computador

CINAHPA | 2017 - Congresso Internacional de Ambientes Hipermídia para Aprendizagem.

Eu procurava simplesmente um mundo de coerência bem provido de referências fixas. A mudança constante que era preciso enfrentar por toda parte nunca me dava tempo de me preparar. É por isso que eu encontrava tanto prazer em fazer e refazer as coisas. (WILLIAMS, 2012, p. 90)

Focadas na tarefa de organizar, ou completar uma sequencia, as crianças autistas utilizam padrões racionais, repetitivos e contínuos, que contribuem para garantir certa estabilidade em um mundo tão dinâmico. Em The believing brain, o psicólogo Michael Shermer afirma que a mente humana possui uma tendência a encontrar padrões mesmo quando eles não existem. Segundo ele, o cérebro evoluiu para ligar pontos do nosso mundo formando padrões de sentido que expliquem por que as coisas acontecem. Esse comportamento pode se observado em crianças com TEA que passam horas alinhando seus brinquedos, viajando em mundos paralelos, ou apenas admirando o leve movimento das bolhas de sabão, semelhantes na forma e brilho, que magicamente flutuam pelo ar, demonstrando encanto com a beleza das formas simples e abstratas como os círculos e as linhas. Representar estes padrões, alinhamentos em projetos ou mesmo reforçar a ideia de continuidade em espaços circulares poderia ser um caminho para uma comunicação mais prazerosa destes usuários com o espaço arquitetônico. Segundo Tuan,

O meio ambiente construído como linguagem tem o poder de definir e aperfeiçoar a sensibilidade. Pode aguçar e ampliar a consciência. Sem arquitetura, os sentimentos sobre o espaço permanecem difusos e fugazes... A forma construída tem o poder de aumentar a consciência do sentido de interior e exterior, intimidade e exposição, vida privada e espaço público. (1977, p. 119)

Os poucos projetos mais específicos para esse público concentram-se, quase que exclusivamente, em ambientes internos de escolas, clínicas ou centros de terapia, sendo que menos ainda tem se pesquisado sobre a importância do ambiente, principalmente externo, para o conhecimento delas sobre o mundo. Além disso, não há uma clara conscientização sobre as diferenças existentes entre os pequenos habitantes das cidades: enquanto as crianças neurotípicas comuns compreendem mais facilmente a partir do todo, as autistas costumam focar mais as partes e os detalhes, o que decorre de características que perturbam suas percepções, limitando, muitas vezes, sua apropriação do mundo.

\section{A expressão usada por Williams, Parem o mundo, eu quero descer!, mostra bem como} pessoas com TEA se sentem vivendo no caos de uma metrópole, dentro do ritmo intenso das ruas de uma cidade, ou tolerando apenas os ruídos de seu bairro.

Apesar de a exploração dos espaços ao ar livre ser algo complicado, e muitas vezes nada prazeroso, para um pequeno autista, o seu isolamento do mundo não deve servisto como uma boa solução.

Pais e cuidadores precisam colocar as crianças no mundo, porque elas não vão se interessar por coisas com as quais não tem contato... Seus pais os deixaram cair numa rotina que nunca varia e não traz experiências novas... Até os autistas com problemas graves precisam ver o mundo... serve estar perto de casa. Não em casa, mas perto de casa. É essencial que a criança saia de casa... (GRANDIN, 2016, p. 194)

Crianças adoram a liberdade, mas precisam da presença de um adulto para livrá-las da ameaça e da sensação de medo que o próprio espaço aberto pode passar. Assim protegidas, desfrutam melhor de sua aventura ao explorar o desconhecido.

Partindo-se do princípio que a insegurança acomete a todos os pequenos, pode-se afirmar que esse sentimento é potencializado no caso de uma criança com TEA, pois que o distúrbio provoca muita confusão na percepção das informações e na interpretação de seus sentidos. E o meio ambiente urbano, cheio de ruídos, odores e poluições visuais, torna-se um
Realização:
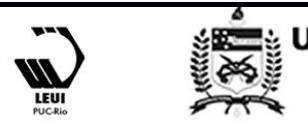
$16^{\circ}$ Ergodesign - Congresso Internacional de Ergonomia e Usabilidade de Interfaces Humano Tecnológica: Produto, Informações Ambientes Construídos e Transporte

$16^{\circ}$ USIHC - Congresso Internacional de Ergonomia e Usabilidade de Interfaces Humano Computador

CINAHPA | 2017 - Congresso Internacional de Ambientes Hipermídia para Aprendizagem.

cenário caótico que provoca instabilidade nesses seres hipersensíveis.

Superar medos e sair da rotina para aumentar o grau de tolerância ao que seja fora do comum são estratégias que devem ser estimuladas não só no trato com os autistas, mas com todas as crianças, com o intuito de promover, de forma ampla, a inclusão e a aceitação ao diferente. As crianças deveriam se incomodar menos ao ver um coleguinha sentindo prazer em repetir inúmeras vezes o mesmo movimento giratório.

Ao invés de julgar, por que não participar do ato lúdico e simplesmente girar com ele? Essa seria uma atitude mais compreensiva e inclusiva do que impedir que o colega siga sozinho com sua estereotipia. Respeitar as pausas de um autista também seria outro bom exemplo de inclusão, em ocasiões em que este preferir sair para se isolar por alguns minutos em um lugar distante. O tempo é extremamente necessário para acalmar os sentidos e recuperar o foco de um portador de TEA, pois as atividades sociais, cheias de informações, deixam-nos muito estressados, obrigando-os a se recolherem momentaneamente em seu mundo particular. Para eles, a segurança de estar só, como dentro de uma concha, é como um grande sonho.

As conchas em espiral não existem somente pela beleza, há outra coisa. Deves compreender que existem vários peixes que têm o focinho tão comprido que comeriam a maioria dos peixinhos se a casa deles fosse reta; mas, quando são assaltados à porta por seus inimigos, ao fugirem para dentro retiram-se em círculos, seguem o trajeto da linha espiral e o fazem de tal modo que seus inimigos não lhes podem fazer mal. (BARCHELARD, 2000, p. 138)

Alguns cuidadores tentam fazer uma ponte entre o isolamento do mundo circunspecto do autista com outros círculos sociais, mas esse processo de interseção entre os dois mundos demanda muita cautela.

[...] o ser é sucessivamente condensação, que se dispersa explodindo, e dispersão, que reflui para um centro. $\mathrm{O}$ exterior e o interior são íntimos: estão sempre prontos a se inverter, a trocar sua hostilidade. Se há uma superfície-limite entre tal interior e tal exterior, essa superfície é dolorosa dos dois lados. (BARCHELARD, 2000, p. 221)

Essa dor da transição entre o espaço interior e o exterior poderia ser bastante amenizada por meio de projetos arquitetônicos adequados. Com exceção de creches ou playgrounds, poucos lugares são planejados para crianças. Em seu livro Espaço e lugar: a perspectiva da experiência (1983), Tuan chama a atenção para o caráter brincalhão e experimental dos movimentos infantis. Observa ainda como os opostos são claramente identificados por crianças com pouco mais de dois anos, deduzindo que a habilidade espacial do corpo precede o conhecimento mental do espaço. Ao movimentar o corpo, a criança absorve lentamente a noção de fenômenos gêmeos opostos, vivenciando experiências tais como: cima/baixo, frente/trás, claro/escuro, interior /exterior etc.

Ainda segundo o autor, no início da vida o ser humano não consegue distinguir entre o eu e o meio ambiente, pois não percebe o mundo fora de si. O primeiro ambiente que o bebê descobre, inicialmente com a boca, depois com as mãos e, posteriormente, com os olhos, é a mãe. Somente em seguida reconhece o interior de sua casa como o lugar de seus brinquedos. Assim, nos primeiros anos de vida, o "aqui" tem um significado maior do que o "lá", pois só com o tempo as crianças vão perceber o jardim e a rua como o exterior. Para os autistas, existe uma grande dificuldade em se posicionar no 'lá', ou seja, no lugar do outro.

A palavra autismo, formada por auto (do gr. referente a si mesmo) + ismo (sufixo que indica ação ou estado), reforça a escassa interação dos indivíduos portadores do distúrbio com seus semelhantes, pois eles se identificam mais com o 'aqui', preferindo a segurança de ambientes mais conhecidos como o interior de suas casas. Enquanto, para a maioria dos bebês, o quarto representa um lugar seguro, fora de casa, esse jovem
Realização:

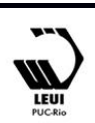


$16^{\circ}$ Ergodesign - Congresso Internacional de Ergonomia e Usabilidade de Interfaces Humano Tecnológica: Produto, Informações Ambientes Construídos e Transporte

$16^{\circ}$ USIHC - Congresso Internacional de Ergonomia e Usabilidade de Interfaces Humano Computador

CINAHPA | 2017 - Congresso Internacional de Ambientes Hipermídia para Aprendizagem.

explorador, solto na amplidão do vazio, experimenta uma mistura de medo e liberdade. Assim, a criança começa a distinguir o lugar como 'pausa' e o espaço como 'movimento'. Experimentar desde cedo os opostos, entre o interior/exterior, pausa/movimento, é de extrema importância para uma coerente estruturação corporal.

Crianças portadoras de TEA não podem ficar limitadas a esta fundamental educação espacial e, por isso, os tratamentos voltados ao autismo deveriam alternar os contatos entre espaços públicos e privados. Muito embora os espaços fechados ajudem essas crianças a focar e aumentar seu tempo de concentração, os familiares e terapeutas não podem deixar de incentivar os movimentos ao ar livre.

Surge assim um alerta, ou talvez um problema a ser pensado com mais cautela: uma linguagem arquitetônica lúdica e abstrata poderia dialogar melhor com os autistas, no sentido de gerar uma empatia destes com seu entorno espacial, passando maior segurança e prazer ao se conectarem com o mundo a sua volta? Que características deveriam ter os ambientes para permitir maior conforto às crianças autistas?

Acredita-se que a arquitetura possua uma capacidade de tocar a sensibilidade humana, podendo ser utilizada como instrumento terapêutico na inclusão de crianças com transtornos de comportamento. Encontros e ocasiões prazerosas são funções fundamentais que não podem ser esquecidas por arquitetos e urbanistas ao projetar cidades e edifícios capazes de beneficiar a interação social e o aprendizado.

No caso dos espaços internos, um esforço nesse sentido vem sendo feito, desde 2008, por Mostafa que, com intuito de formular diretrizes para o projeto, enumera sete requisitos fundamentais para ambientes residenciais voltados à essa demanda: acústicos, sequenciamento espacial, espaço de fuga, compartimentalização, transições, zoneamento sensorial e segurança. No que diz respeito à audição, o ambiente acústico deve ser pensado de forma a minimizar o ruído de fundo, o eco e a reverberação. O que a autora chama de sequenciamento espacial diz respeito à organização lógica das áreas internas, baseada na programação horária de uso desses espaços. Segundo Mostafa, deve-se poder fluir, o mais perfeitamente possível, de uma atividade para a outra por meio de uma circulação unidirecional com o mínimo de interrupções. $\mathrm{O}$ objetivo do espaço de fuga, que pode ser um pequeno abrigo em uma área tranquila de um comodo ou em todo um edifício, é proporcionar aos autistas um descanso da superestimulação encontrada nos seus ambientes de vivência. Ele deve ser um ambiente sensorialmente neutro, com estimulação mínima que pode ser personalizada pelo usuário para fornecer as condições ambientais necessárias a cada caso.

\section{A compartimentalização se refere à} necessidade de que cada ambiente possua uma função clara e uma apropriada qualidade sensorial, ou seja, "a place for everything and everything in its place” (Mostafa, 2008, p. 204). A zona de transição ajuda o usuário a recalibrar suas energias sensoriais no caso de mudar de um determinado nível de estímulo para outro. Por meio do zoneamento, pretendese que os ambientes sejam projetados de acordo com as percepções sensoriais dos usuários ao invés de serem baseados em zonas funcionais ordinárias e generalizantes. Finalmente, a autora recomenda um cuidado especial com a segurança dos ambientes projetados para crianças autistas, as quais possuem um sentido alterado em relação ao seu entorno.

No entanto, não existem ainda propostas específicas para os espaços ao ar livre adequados ao uso dos autistas. Os playgrounds a céu aberto são espaços de transição entre a casa e o caos urbano, que podem assegurar a proteção e o conforto dos quartos infantis cheios de brinquedos e, ao mesmo tempo, promover maior liberdade de movimento das 


\section{$16^{\circ}$ \\ ERGODESIGN USIHC CINAHPA}

crianças em seus bairros. $\mathrm{O}$ apelo ao lúdico constitui uma delicada fórmula para neutralizar a dor e a resistência observadas nos tratamentos de inclusão dos portadores de TEA. Terapeutas e educadores mais sensíveis, como, os adeptos de programas de ensino estruturado para pessoas com autismo - Son-Rise, ABA (Applied Behavior Analysis) e TEACCH (Treatment and Education of Autistic and Communication related Handicapped Children) - respeitam o processo criativo infantil, aproveitando-se dele para tentar ler os símbolos e as mensagens subliminares que as crianças conseguem passar em seus momentos lúdicos. De acordo com o método norteamericano Son-Rise - Aprender brincando -, a dinâmica parte do interesse particular de cada paciente, e o prazer constitui o ponto de partida para promover o contato de crianças com o próximo e o mundo. De maneira sistemática, os terapeutas avaliam primeiramente as mínimas motivações destas crianças, depois estudam quais recompensas as ajudariam a dar respostas mais eficientes.

As crianças sempre brincam com muita concentração. O jogo é capaz de absorver inteiramente o jogador, que se desconecta da realidade do dia a dia e mergulha em um mundo paralelo. Para Huizinga (1938), tanto as crianças como os animais brincam por prazer e daí resulta sua sensação de liberdade. Brincar é uma forma eficaz de aprendizagem, já que o jogo constitui uma manipulação de imagens, uma certa 'imaginação' da realidade, ou seja, uma transformação desta realidade em imagens. Jogar é literalmente colocar para fora o que vemos dentro da nossa cabeça, ou seja, a imagem em ação.

Eu provia minha própria educação. Vagava muitas vezes pelos arredores da escola. Cada escapadela me arrastava a outra aventura... Eu não ia a lugar nenhum em particular.

Simplesmente ia. Subia as escadas das torres, brincava no elevador ... Brincava nas paradas de bonde... Aprendi uma porção de coisas desta maneira. (WILLIAMS, 2012, p. 126) $16^{\circ}$ Ergodesign - Congresso Internacional de Ergonomia e Usabilidade de Interfaces Humano Tecnológica: Produto, Informações Ambientes Construídos e Transporte

$16^{\circ}$ USIHC - Congresso Internacional de Ergonomia e Usabilidade de Interfaces Humano Computador

CINAHPA | 2017 - Congresso Internacional de Ambientes Hipermídia para Aprendizagem.

Aprender ao brincar e explorar o entorno de forma lúdica induz à necessidade de dialogar com o mundo, mesmo considerando a dificuldade que a maioria dos portadores de TEA têm de comunicar o que pensam por meio da fala.

Eu quero falar para você agora sobre diferentes modos de pensar. Você tem que fugir da linguagem verbal. Eu penso em imagens. Eu não penso em linguagem falada. Agora a coisa sobre a mente autista é que ela se prende aos detalhes, e o cérebro normal ignora os detalhes. As pessoas estão deixando de fazer as coisas com as mãos. Eu estou realmente preocupada, pois muitas escolas têm tirado as aulas de trabalhos manuais, porque arte e aulas como estas, eram onde eu era excelente. (GRANDIN, 2010)

Maneiras de expressão mais lúdicas podem substituir a linguagem falada, contribuindo sobremaneira para que uma criança especial possa expor suas emoções. Brincar com a linguagem corporal no esporte ou no teatro; interagir com o ritmo da música, dançando ou tocando um instrumento; fazer esculturas, pinturas ou desenho são caminhos eficazes na busca de uma linguagem que se adapte ao perfil de cada ser humano.

Muitos tratamentos usam Terapias Ocupacionais na busca do equilíbrio dos sentidos de seus pacientes, sendo que alguns pais recorrem à musicalização ou às artes visuais como auxiliares no desenvolvimento da expressão de seus filhos.

Um dos primeiros registros da introdução da arteterapia em tratamentos psiquiátricos no Brasil ocorreu, no início da década de 1950, no Hospital Psiquiátrico Pedro II, no Rio de Janeiro. Nas sessões de terapia ocupacional, chamou a atenção da psiquiatra Nise da Silveira a presença de uma linguagem universal nas representações gráficas de seus pacientes: o círculo. Em cartas ao mestre Jung, Nise comentou a curiosa repetição, nas pinturas de vários internos, do uso de mandalas, que surgiam, quase sempre, nas horas mais 
$16^{\circ}$ Ergodesign - Congresso Internacional de Ergonomia e Usabilidade de Interfaces Humano Tecnológica: Produto, Informações Ambientes Construídos e Transporte

$16^{\circ}$ USIHC - Congresso Internacional de Ergonomia e Usabilidade de Interfaces Humano Computador

CINAHPA | 2017 - Congresso Internacional de Ambientes Hipermídia para Aprendizagem.

tranquilas, em que o cérebro, parecendo organizar melhor as ideias, fazia uso de formas geométricas, durante o prazeroso ato de pintar ao som de música clássica.

A tendência à geometrização também foi observada em 1926, pelo psicólogo alemão Heinrich Kluver, ao concluir que a maioria das alucinações visuais se encaixavam em algumas categorias da geometria básica, como quadrículas, triangulos e espirais. Outro pesquisador da Universidade da Califórnia, o matemático Jack Cowan, em um artigo para a New Scientist (1983), destacou que, como as alucinações ocorriam independente dos olhos, a fonte das imagens não estava na retina, mas no próprio córtex visual.

O que isso indica é que quando você vê padrões geométricos, a arquitetura do seu cérebro deve refletir esses padrões e, portanto, deve ser geométrica.(apud GRANDIN 2016, p. 162)

O gesto circular, símbolo universal e uma das formas geométricas mais representadas pelo ser humano, está presente nos desenhos de quase todas as crianças em suas primeiras garatujas. Os círculos surgem com o natural movimento dos braços e das mãos, e os pequenos parecem se encantar com a ideia de ver algo se fechando: linhas circulares, que marcam o diferente como um lugar; um objeto independente do vazio, que nasce da folha em branco.

Como uma forma pura e simbólica, o círculo adquire, no desenho infantil, vários significados, podendo expressar de sol até mesmo pessoas. Mais que uma tentativa de representar a realidade, exprime um sentimento. Muitos artistas tinham plena consciência de que atingiriam seu auge criativo quando resgatassem o seu espírito lúdico, ou quando voltassem a pensar como crianças, como confessou Picasso: "Quando tinha 15 anos, sabia desenhar como Raphael, mas precisei uma vida inteira para desenhar como criança" (apud VASCONCELLOS, 2007, p. 69).
Assim como esse pintor catalão que, rompendo com a tradição da pintura européia, introduziu o cubismo e as abstrações geométricas, principalmente após o contato com a arte africana, outros artistas da vanguarda do século XX buscaram novas formas de expressão artística, para fugir das limitações da representação figurativa da realidade e também na tentativa de melhor se identificar com o novo mundo que se anunciava.Worringer, em seu livro Abstração e Natureza (1908), sugere que a linguagem abstrata, após a Primeira Guerra, tenha surgido por receio ou fuga da realidade, em contraponto com as representações figurativas encontradas, sobretudo, em culturas onde as pessoas tiveram mais empatia com o mundo. De fato, muitos artistas, buscando fugir da crueldade do pósguerra, mergulharam conscientemente na geometrização e na busca de uma utopia que os distanciasse do cenário de mortes e destruições. A decepção com um mundo capaz de produzir uma guerra entre povos irmãos levou muitos intelectuais e artistas a se debruçarem sobre a busca de uma nova linguagem para um novo homem, por meio da abstração e da geometrização.

A rejeição à realidade também constitui uma das características dos autistas, não no sentido consciente de expressar uma negação à agressão dos seres humanos, mas simplesmente para evitar a enorme quantidade de informação que o mundo real os apresenta. Viver no mundo dos sonhos, onde imagens mais divertidas aparecem para dar sentido às suas utopias, pode ser uma maneira lúdica que encontram para sobreviver no dia a dia.

Formas abstratas, figuras geométricas e padrões repetitivos parecem ser elementos que adquirem o caráter de linguagem universal, de grande potencial, em seu mundo comunicativo, como descrito por William:

Eu via de novo o mundo fragmentado e em pequenos pedaços. Só percebia figuras geométricas de motivos atraentes: triângulos verdes, quadrados dourados ou simplesmente o

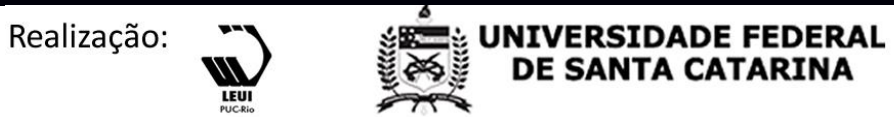


$16^{\circ}$ Ergodesign - Congresso Internacional de Ergonomia e Usabilidade de Interfaces Humano Tecnológica: Produto, Informações Ambientes Construídos e Transporte

$16^{\circ}$ USIHC - Congresso Internacional de Ergonomia e Usabilidade de Interfaces Humano Computador

CINAHPA | 2017 - Congresso Internacional de Ambientes Hipermídia para Aprendizagem.

azul, no qual meu olhar mergulhava com deleite." (2012, p. 114)

Partindo desta hipótese, acredita-se que locais belos, lúdicos e abstratos, como os playgrounds de Van Eyck e algumas áreas de lazer nas quadras residenciais de Brasília, ou outros exemplos de parques contemporâneos, sirvam como modelos a serem estudados como contribuição e inspiração para futuros espaços mais inclusivos. Tem se observado que nos playgrounds mais abstratos, criados a partir de volumes geométricos simples, as formas adquirem a capacidade de se tornar um canal de comunicação universal, o que não somente contribui para desenvolver a imaginação das crianças em geral, como atende à necessidade dos portadores de TEA, no que diz respeito à possibilidade de interagir com o mundo.

Infelizmente, grande parte dos atuais espaços urbanos não são pensados para oferecer beleza e prazer ao público. Construções, em geral áridas e cheias de muros, reproduzem os tradicionais lotes individualizados que, privilegiando uma suposta segurança, contribuem para perpetuar a febre de criar condomínios desagregados do contexto urbano e de oferecer paraísos artificiais isolados. Os espaços externos acabam sendo subutilizados pelos escassos transeuntes, que preferem se deslocar no conforto do ar-condicionado de seus carros, restando à cidade apenas o papel de autopistas de rápida conexão.

Se passear pelo espaço urbano já não é uma tarefa naturalmente agradável para a maioria dos indivíduos, imaginem para portadores de TEA! Carros e motos barulhentas a toda velocidade pelas ruas, muros pichados, poluição visual pelo excesso de propagandas, calçadas quebradas, sombras escassas e praças abandonadas constituem fatores de constante ameaça. Os poucos playgrounds cercados, quase sempre 'depósitos' de crianças barulhentas, estão longe de ser uma área convidativa para os autistas, que evitam o contato com a multidão. Talvez por isso, alguns pais achem mais seguro manter seus filhos isolados em suas casas. Diante desse quadro, é importante fazer um alerta sobre a importância de se criar um mundo, onde os pais também possam compartilhar momentos agradáveis ao ar livre com seus filhos.

Pode-se aprender muito com o importante conceito de A Cidade como Playground do arquiteto Aldo Van Eyck, para quem “[...] a arquitetura tem que facilitar a atividade humana e promover a interação social." (apud OUDENAMPSEN, 2009). Ao projetar mais de setecentos playgrounds, entre 1947 e 1978, o arquiteto holandês assumiu um compromisso com a criação de espaços que pudessem ajudar na interação entre adultos e crianças. Com o intuito de melhorar a qualidade de vida urbana para inúmeras crianças órfãs da Amsterdã do pós-guerra, seus equipamentos baseavam-se em formas simples e abstratas, de modo a permitir a fluidez da imaginação infantil. Com as interpretações em aberto, cada um dos pequenos usuários podia se apropriar subjetivamente do espaço intersticial, com composições não hierárquicas, que conduziam a uma arquitetura fluida de fácil adaptação à vida cotidiana de bairro.

\footnotetext{
Van Eyck pensava na cidade ideal como um labirinto de pequenos territórios íntimos ou, mais poeticamente, como uma constelação casual de estrelas. Um playground em cada esquina era apenas um primeiro passo para a 'cidade lúdica', a cidade da brincadeira [...] Por mais que espaço e tempo sejam importantes, lugar e ocasião importam mais. Pois na mente do homem, o espaço é o lugar e o tempo é a ocasião. Como as pessoas podem fazer do espaço algo próprio e criar um 'sentido de lugar' subjetivo? O playground, espaço intermediário entre o público e o privado, é lugar e ocasião combinados. (ROSA, abr. 2013)
}

Assim como as formas geométricas de Van Eyck, pensadas para estimular a criatividade e a imaginação infantil, ambientes exemplares com características lúdicas perfeitamente inclusivas foram criados por arquitetos brasileiros. Entre 1950 e 1960, um dos períodos mais expressivos da cultura brasileira,

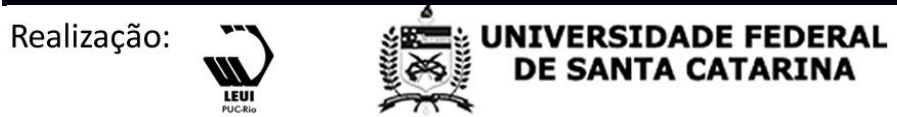


$16^{\circ}$ Ergodesign - Congresso Internacional de Ergonomia e Usabilidade de Interfaces Humano Tecnológica: Produto, Informações Ambientes Construídos e Transporte

$16^{\circ}$ USIHC - Congresso Internacional de Ergonomia e Usabilidade de Interfaces Humano Computador

CINAHPA | 2017 - Congresso Internacional de Ambientes Hipermídia para Aprendizagem.

mestres modernistas, como Lucio Costa, Oscar Niemeyer, Athos Bulcão e outros, acreditaram na possibilidade de conceber espaços residenciais agradáveis para os moradores da nova capital, utopia essa que se traduziu nas Unidades de Vizinhança.

Na Superquadra 308 Sul, que integra a primeira dessas unidades concluída na cidade, a redução da área de uso dos veículos foi possível graças à diminuição do número de blocos de onze para nove e da construção de garagens subterrâneas. Construídos sobre pilotis, os blocos liberam espaços livres e sombreados, que se articulam com praças, espelhos d'água, murais de azulejos, áreas verdes projetadas por Roberto Burle Marx, e passeios seguros e agradáveis, que dão acesso às escolas, à biblioteca pública, à igreja, às quadras de esporte e ao clube de vizinhança.

Atualmente considerada modelo, essa superquadra constitui um exemplo de que utopias podem se tornar realidades e de que é possível aliar urbanismo, arquitetura, paisagismo e arte na construção de espaços prazerosos e funcionais, que valorizem a paisagem e respeitem a escala de vizinhança. Passando maior segurança e criando sensações de abrigo em recantos e lugares onde o tempo se transforma em ocasião, essa escala, mais próxima da infantil, permite a vivência e o registro de experiências perceptivas, que ajudam na construção do conhecimento sobre o mundo.

A importância da menção desse espaço em Brasília deve-se ao estudo de caso que, baseado em observações sistemáticas, atesta a grande evolução no tratamento do filho de uma das autoras, de sete anos, portador de TEA. Pretende-se deixar aqui registrada uma lembrança aos colegas arquitetos, sobre a força transformadora que existe por trás das formas abstratas dos espaços arquitetônicos.

\section{CONCLUSÃO}

Um importante desafio que aqui se coloca é o de, dando continuidade ao trabalho de Mostafa, não somente avaliar como estender suas diretrizes para os espaços ao ar livre. Nesse sentido, cabe pensar soluções arquitetônicas e urbanísticas para espaços de vivência externa, onde possam ser minimizados os ruídos da cidade. Espaços esses que devem ser bastante organizados, e também compartimentalizados em função das atividades que ali serão desenvolvidas. Merece cuidado ainda a definição dos interstícios de transição entre atividades diferenciadas. Mais importante, no entanto, é estabelecer os locais de fuga necessários ao repouso mental das crianças autistas, mas que sem dúvida, são também locais privilegiados e que atraem as crianças em geral, pela capacidade de alimentar suas fantasias individuais.

Os primeiros passos, que já vem sendo dados, consistem em levantar e analisar, ergonomicamente e do ponto de vista do conforto ambiental, espaços existentes projetados com o intuito de servir de suporte às brincadeiras infantis. Em seguida, trata-se de verificar em que medida os critérios estabelecidos por Mostafa, ao serem confrontados com esses espaços, atendem aos requisitos específicos do público-alvo no que se refere à vivência ao ar livre. A partir daí, surgirão os pontos de apoio capazes de dar suporte às diretrizes de projeto para novos espaços do brincar e do aprender livres, abertos e inclusivos.

Do ponto de vista metodológico, a partir das informações colhidas tanto na bibliografia especializada quanto nas narrativas das próprias crianças autistas em relação a sua percepção do mundo, objetiva-se formular um instrumento, que possa dar subsídios para projetos de espaços livres mais lúdicos e inclusivos. O próximo passo seria desenvolver algumas sugestões de partidos para alguns lugares específicos, previamente definidos no corpo da pesquisa. 


\section{$16^{\circ}$ \\ ERGODESIGN USIHC CINAHPA}

\section{REFERÊNCIAS}

ABRAHÃO, Julia [et alli.]. Introdução à ergonomia: da prática à teoria. São Paulo: Blucher, 2009.

BACHELARD, Gastón. A poética do espaço. São Paulo: Brasiliense, 2000.

BATISTAS, Jairo. A imagem de Brasília nas crianças. Dissertação de mestrado. Brasília: UnB, 2003.

BERMAN, Tali F.; RAPPAPORT, Abby.

Brincar para crescer: 201 atividades projetadas para ajudar crianças especiais a desenvolver habilidades sociais

fundamentais. Tubarão: Copiart, 2010. FONSECA, Maria Elisa Granchi. Vejo e aprendo: fundamentos do Programa TEACCH. Ribeirão Preto: Book Toy, 2014. GRANDIN, TEMPLE. $O$ mundo necessita de todos os tipos de mentes. Entrevista TED, 2010.

https://www.ted.com/talks/temple grandin the _world needs all kinds of minds/transcript?1 anguage $=\mathrm{pt}-\mathrm{br}$

GRANDIN, Temple; PANEK, Richard. O cérebro autista: pensando através do espectro. Rio de Janeiro: Record 2016. HUIZINGA, Johan (1938). Homo ludens. São Paulo: Perspectiva, 2000.

LEBOYER, Marion. Autismo infantil. Fatos e modelos. Campinas: Papirus, 2005.

MOSTAFA, Magda. An architecture for autism: concepts of design intervention for the autistic user. Archnet-IJAR. International Journal of Architectural Research, vol. 2, issue 1, março 2008. http://www.archnetijar.net/index.php/IJAR/article/viewFile/182/2 $\underline{46}$ An architecture for autism: application of the autism aspects design index to home environment. The International Journal of the Constructed Environment, vol. 20, 2014. Illinois: Common Ground Publishing.

https://www.researchgate.net/publication/2853 45382 An Architecture for Autism Applicat ion_of_the_Autism_ASPECTS_Design_Index to_Home_Environments $16^{\circ}$ Ergodesign - Congresso Internacional de Ergonomia e Usabilidade de Interfaces Humano Tecnológica: Produto, Informações Ambientes Construídos e Transporte

$16^{\circ}$ USIHC - Congresso Internacional de Ergonomia e Usabilidade de Interfaces Humano Computador

CINAHPA | 2017 - Congresso Internacional de Ambientes Hipermídia para Aprendizagem.

OUDENAMPSEN, Merijn. A cidade como playground. Belo Horizonte: Revista Piseagrama $\mathrm{n}^{\circ}$. 03, 2009.

PALLASMAA, Juhani. As mãos inteligentes: a sabedoria existencial e corporalizada na arquitetura. Porto Alegre: Bookman, 2013. ROSA, Marcos. Revisitando os playgrounds de Aldo van Eyck, 1947- 2011. Vitruvius. 074.02 ano 07, abr. 2013.

http://www.vitruvius.com.br/revistas/read/arqu iteturismo/07.074/4707

SANS, Paulo de Tarso Cheida. Pedagogia do desenho infantil. São Paulo: Alínea, 2007. SHERMER, Michael. The believing brain: from ghosts and gods to politics and conspiracies---how we construct beliefs and reinforce them as truths. New York: Times Books, 2011.

TUAN, Yi-Fu (1977). Espaço e lugar: a perspectiva da experiência. São Paulo: Difel, 1983.

VASCONCELLOS, Marina da C. M. Quando a Psicoterapia Trava. São Paulo: Summus, 2007.

WILLIAMS, Chris. Convivendo com autismo e síndrome de Asperger: estratégias práticas para pais e profissionais. São Paulo: M.

Books, 2008.

WILLIAMS, Donna. Meu mundo misterioso: testemunho excepcional de uma jovem autista. Brasília: Thesaurus, 2012. WORRINGER, Wilhelm. Abstracción y naturaleza. México: Fondo de Cultura Económica, 1953.

Realização:

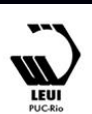

